\title{
Temozolomide inhibits cellular growth and motility via targeting ERK signaling in glioma C6 cells
}

\author{
YINGGE WANG $^{1-5}$, SHAN GAO ${ }^{6}$, WEIGUANG WANG ${ }^{7}$ and JINGYAN LIANG ${ }^{2-4,8}$ \\ ${ }^{1}$ Department of Clinical Medicine, College of Medicine; ${ }^{2}$ The Research Center for Vascular Biology, \\ College of Medicine; ${ }^{3}$ Jiangsu Key Laboratory of Integrated Traditional Chinese and Western Medicine \\ for Prevention and Treatment of Senile Disease, Yangzhou University, Yangzhou, Jiangsu 225001; \\ ${ }^{4}$ Jiangsu Co-Innovation Center for the Prevention and Control of Important Animal Infectious Disease and Zoonoses, \\ Yangzhou University, Yangzhou, Jiangsu 225009; ${ }^{5}$ Mobile Post-Doctoral Research Station of Yangzhou University; \\ ${ }^{6}$ Department of Neurological, Shanghai JiaoTong University Affiliated The Sixth People Hospital, South Campus, \\ Shanghai 200233; ${ }^{7}$ Department of Hematology, First Affiliated Hospital of Jiamusi University, Jiamusi, Heilongjiang 154003; \\ ${ }^{8}$ Department of Anatomy, College of Medicine, Yangzhou University, Yangzhou, Jiangsu 225001, P.R. China
}

Received August 15, 2015; Accepted August 8, 2016

DOI: $10.3892 / \mathrm{mmr} .2016 .5964$

\begin{abstract}
Temozolomide (TMZ) is an alkylating agent used for the treatment of aggressive forms of brain tumor based on its antitumor actions. However, the exact effect on cancer and the underlying anticancer molecular mechanism of TMZ remain to be elucidated. In the present study, the effects of TMZ on the growth and motility of glioma C6 cells were investigated. MTT and Transwell assays were used to detect cellular growth and motility. The results showed that TMZ inhibited the proliferation, migration and invasion of the glioma C6 cells in vitro, western blot analysis determined that the phosphorylation of extracellular signal-regulated protein kinase (ERK)1/2 was decreased in the TMZ-treated cells, compared with the untreated control cells. The ERK1/2 specific inhibitor, U0126, augmented the inhibitory effects of $\mathrm{TMZ}$ on the proliferation, migration and invasion of the glioma C6 cells, and the mitogen-activated protein kinase kinase/ ERK pathway activator, curcumin, attenuated the inhibitory effects of TMZ on the proliferation and motility of the glioma C6 cells. Additionally, the western blotting in the present study demonstrated that TMZ and U0126 decreased the expression of vascular endothelial growth factor-C (VEGF-C), and the expression level was restored by curcumin, suggesting that VEGF-C may be the downstream effector of ERK1/2. Furthermore, the overexpression of VEGF-C enhanced the
\end{abstract}

Correspondence to: Dr Jingyan Liang, The Research Center for Vascular Biology, College of Medicine, Yangzhou University, 11 Huaihai Road, Guangling, Yangzhou, Jiangsu 225001, P.R. China E-mail: jingyan1008@163.com; jyliang@yzu.edu.cn

Key words: temozolomide, extracellular signal-regulated kinase $1 / 2$, vascular endothelial growth factor-C, proliferation, migration, invasion growth, migration and invasion of the TMZ-treated cells. These results suggested that TMZ suppressed glioma C6 cell development, at least in part, and downregulated the expression of VEGF-C by inhibiting the ERK signaling pathway. The results of the present study provides the foundation for a combinational therapeutic strategy to improve the efficacy of TMZ.

\section{Introduction}

Glioma is one of the common types of primary intracranial tumor in humans (1). Gliomas account for $\sim 30 \%$ of all types of brain and central nervous system tumor and $80 \%$ of all types of malignant brain tumor (2). It often spreads via the cerebrospinal fluid, metastasizes to the spinal cord and the normal brain tissue, and forms a satellite tumor group around the primary tumor due to its uncontrolled aggressive growth and invasion. Despite developments in surgery, chemotherapy, radiotherapy and combined treatment modalities, curing glioma completely remains a challenge (3-5). The median survival rate is generally $<1$ year due to the high rate of recurrence following surgery and poor prognosis (3-6). Therefore, it is necessary to investigate novel potential therapeutic agents and elucidate the molecular mechanisms underlying their cytotoxic effect via clinical investigations. Temozolomide (TMZ) is an imidazotetrazine derivative of the alkylating agent. dacarbazine. TMZ exhibits schedule-dependent antineoplastic activity by interfering with DNA replication and demonstrates activity against recurrent glioma $(7,8)$. However, for reasons that remain to be elucidated, clinical response is poor. Therefore, the exact effect of TMZ on the malignancy of glioma cells and the underlying mechanism require investigation.

The mitogen-activated protein kinase (MAPK) signaling pathways are global regulators of cellular responses to stress, which transduce signals through subsequent phosphorylation events, culminating in the phosphorylation of the terminal 
MAPK and altered cellular transcription profiles. There are three major MAPK pathways, and the respective terminal MAPKs in these are p38, c-Jun N-terminal kinase (JNK) and extracellular signal-regulated kinase (ERK)1/2 or MAPK 42/44 (9). The ERK pathway is activated by receptor tyrosine kinases through the small $G$ protein, Ras. The activation of Ras leads to the phosphorylation of Raf, which in turn phosphorylates MAPK kinase (MEK)1/2, a dedicated dual-specificity kinase that regulates the phosphorylation of ERK1/2 by tyrosine and threonine residues (10). Activated ERK1/2 can translocate into the nucleus, where it stimulates numerous transcription factors involved in cell survival, apoptosis, differentiation and motility (11).

A number of molecules often exhibit abnormalities in the pathogenesis of glioblastoma. For example, the upregulation and/or constitutive activation of growth factors, including epidermal growth factor (EGF), hepatocyte growth factor (HGF), vascular endothelial growth factor (VEGF), and the growth factor receptors, EGFR and HGFR, are often involved in the abnormal growth and motility of glioma cells (12-16). Certain signaling cascades, particularly MEK/ERK1/2 and phosphoinositide 3-kinase/AKT are critical in the molecular abnormalities. In addition, ERK1/2 exhibits constant constitutive activation upon alterations of tyrosine kinase receptors in glioblastoma (17-22). As anticancer drugs often affect various signal transduction pathways, including those associated with tumor growth, cell death and metastasis, targeting specific signaling pathways is a strategy for the development of cancer therapy (23-26). Thus, certain selective inhibitors of pathways or molecules associated with the progression and development of glioblastoma have been considered as molecular targeting agents in cancer therapy. U0126, an ERK1/2-specific inhibitor, can significantly inhibit the activation of ERK and suppress ERK signaling (27-29). Therefore, it may be necessary to use molecular inhibitors for effective tumor treatment.

TMZ is a standard chemotherapeutic agent for the treatment of glioblastoma multiforme, however, the exact effect of $\mathrm{TMZ}$ on glioma remains to be fully elucidated In the present study, the effects of TMZ on the growth and motility of glioma C6 cells were investigated, and whether the ERK signaling pathway is involved in its regulation was examined.

\section{Materials and methods}

Cell culture. The rat glioma C6 cbiell line was obtained from American Type Culture Collection (Vanassas, MA, USA). The HEK 293T cell line was stored in the Research Center for Vascular Biology (Yangzhou University, Yangzhou, China), which was used to generate adenoviral vectors. These cells were grown in Dulbecco's modified Eagle's medium (DMEM; Gibco; Thermo Fisher Scientific, Inc., Waltham, MA, USA) supplemented with $5 \%$ fetal bovine serum (FBS; Lonza, Levallois-Perret, France) in a humidified atmosphere containing $5 \% \mathrm{CO}_{2}$ at $37^{\circ} \mathrm{C}$.

Cell proliferation assay. Cell proliferation was assessed using an MTT assay. The MTT assay was performed using a 96-well plate according to the manufacturer's protocol. The cells were seeded at a density of $10^{4}$ cells per well and were cultured at $37^{\circ} \mathrm{C}$ with $5 \% \mathrm{CO}_{2}$ for $24 \mathrm{~h}$, following which 250, 500 and 1,000 $\mu \mathrm{M}$ TMZ (Sigma-Aldrich; Merck Millipore, Darmstadt, Germany) was added to the culture for $48 \mathrm{~h}$ or $500 \mu \mathrm{M} \mathrm{TMZ}$ for 24,48 and $72 \mathrm{~h}$. The cells were then incubated with $20 \mu \mathrm{l}$ of MTT $(5 \mathrm{mg} / \mathrm{ml}$ in phosphate-buffered saline) for $4 \mathrm{~h}$ at $37^{\circ} \mathrm{C}$, following which the cells were lysed by the addition of $200 \mu \mathrm{l}$ dimethylsulfoxide. The absorbance was measured at $570 \mathrm{~nm}$ using a Rainbow microplate reader (Tecan Austria GmbH, Salzburg, Austria).

Migration and invasion assays. Cell migration was assessed using Transwell chambers $(6.5 \mathrm{~mm}$; Corning Incorporated, Corning, NY, USA) with $8 \mu \mathrm{m}$ pore membranes. The lower chamber was filled with $600 \mu 1 \mathrm{DMEM}$ medium with or without TMZ. The cells $\left(5 \times 10^{4}\right)$ were suspended in $100 \mu \mathrm{l}$ of DMEM medium with $1 \%$ FBS and plated into the upper chamber, with or without 250,500 and $1,000 \mu \mathrm{M}$ TMZ for incubation at $37^{\circ} \mathrm{C}$. After $20 \mathrm{~h}$, the number of cells visible on the undersurface of the polycarbonate membranes following crystal violet staining was scored in six randomly selected visual fields (magnification, x100) using a light microscope. For invasion assays, the upper surface of the membrane was covered with $70 \mu \mathrm{l}$ of Matrigel $(1 \mathrm{mg} / \mathrm{ml}$; BD Biosciences, Franklin Lakes, NJ, USA). The procedure of the invasion assay was the same as that for the migration assay, with the exception that the incubation duration was extended to $24 \mathrm{~h}$.

Western blot analysis. The cells were lysed in cell lysis buffer for western blot analysis and immunoprecipiation (cat. no. P0013; Beyotime Institute of Biotechnology, Haimen, China) containing a protease inhibitor cocktail (Roche Diagnostics, Branchburg, NJ, USA). Cell lysate was centrifuged at $10,000 \times \mathrm{g}$ for 10 min and the supernatant was collected. Protein samples were quantified using BCA Protein Assay kit (Beyotime Institute of Biotechnology, Jiangsu, China). The protein samples (50 $\mu \mathrm{g})$ were separated by $12 \%$ SDS-PAGE and transferred onto Immobilon-P membranes (EMD Millipore, Billerica, MA, USA). The membranes were blocked with 5\% BSA (Sigma-Aldrich; Merck Millipore) in Tris-buffered saline Tween-20 (TBST) for $1 \mathrm{~h}$, and incubated with specific primary antibodies overnight at $4{ }^{\circ} \mathrm{C}$ and then washed for 3 times with TBST, followed by incubation with horseradish peroxidase (HRP)-conjugated secondary antibodies for $2 \mathrm{~h}$ at room temperature. Anti-ERK rabbit polyclonal antibody (1:1,000; cat. no. 9102), anti phosphorylated (p)-ERK pAb (1:1,000; cat. no. 9101), anti-p-p38MAPK mouse monoclonal antibody (1:1,000; cat. no. 5140), anti-p-JNK mouse $(1: 2,000$; cat. no. 9255) and anti-VEGF-C rabbit pAb $(1: 1,000$; cat. no. 2445$)$ were the primary antibodies used for detection of target proteins, all obtained from Cell Signaling Technology, Inc. (Danvers, MA, USA). HRP-conjugated goat anti-rabbit IgG secondary antibody (1:2,000, cat. no. 7074), horse anti-mouse IgG (1:2,000, cat. no. 7076) were used and were obtained from Cell Signaling Technology, Inc. Enhanced chemiluminescence-detecting reagent (Amersham; GE Healthcare Life Sciences, Chalfont, UK) was used for development. GAPDH was probed using anti-GAPDH rabbit $(1: 1,000$, cat. no. 2118, Cell Signaling Technology, Inc.) as a loading control. The protein blots were quantified by densitometry using QuantityOne software version 4.5.0 (Bio-Rad Laboratories, Inc., Hercules, CA, USA), and the quantity expressed was relative to the corresponding target protein. 
Expression of recombinant $V E G F-C$. The recombinant human VEGF-C was purchased from R\&D Systems, Inc. (Minneapolis, MN, USA).The VEGF C cDNA was amplified by La Taq DNA polymerase (Takara Biotechnology Co., Ltd., Shanghai, China) in polymerase chain reaction (PCR) system with La Taq buffer and $2.5 \mathrm{mM}$ dNTP (Takara Biotechnology Co., Ltd.) using the following primers: VEGF-C forward, 5'-AGTGTCAGGCAGCGAACAAGA-3'. and reverse, 5'-CTTCCTGAGCCAGGCATCTG-3'. PCR thermocycler 9700 (Applied Biosystems) was used with the following regimen of thermal cycling: stage 1,1 cycle, $10 \mathrm{~min}$ at $95^{\circ} \mathrm{C}$; stage 2,40 cycles, $15 \mathrm{sec}$ at $95^{\circ} \mathrm{C}, 1 \mathrm{~min} 60^{\circ} \mathrm{C}$. The PCR products were cloned into a DL7001 Ad 5 adenoviral vector (Vector Core of Human Gene Therapy Institute, University of Pennsylvania, Philadelphia, PA, USA). Answer: HEK 293T cells were transfected by adenoviral vector using Lipofectamine 2000 (Invitrogen;Thermo Fisher Scientific, Inc.) in cell culture dishes. The recombinant viruses were generated in HEK 293T cells and were used for infection of the glioma C6 cells at $37^{\circ} \mathrm{C}$. After $24 \mathrm{~h}$, the cells were used for the experiments. A control cell line was constructed using the LacZ/Ad-5 control vector (Vector Gene Technology Company Co., Ltd., Beijing, China).

Statistic analysis. All the experiments were repeated at least three times. Statistical significance was analyzed using the SPSS 11.0 software program (SPSS, Inc., Chicago, IL, USA). Data were analyzed using Student's t-test. $\mathrm{P}<0.05$ was considered to indicate a statistically significant difference. Data are presented as the mean \pm standard error of the mean.

\section{Results}

TMZ inhibits the proliferation of glioma C6 cells. To determine whether TMZ affects cell viability, the glioma C6 cells were grown in serum-containing medium for $24 \mathrm{~h}$, and were then either treated with TMZ at various concentrations for $48 \mathrm{~h}$ or were treated with $500 \mu \mathrm{M} \mathrm{TMZ}$ for different durations. An MTT assay was then used for the analysis of cell proliferation. The results indicated that the proliferation of the glioma C6 cells treated with TMZ decreased in a concentration- and time-dependent manner, compared with the untreated control cells (Fig. 1A and B).

TMZ attenuates the migration and invasion of glioma C6 cells. The effect of TMZ on glioma C6 cell motility was determined by the detection of cell migration and invasion in vitro. The Transwell assays indicated that the number of cells able to migrate into the lower chambers decreased markedly in the TMZ group as the concentration of TMZ gradually increased, compared with the control group (Fig. 2A and B). These data showed that TMZ significantly suppressed the migration and invasion of glioma C6 cells in vitro in a concentration-dependent manner.

TMZ decreases oncogenic phenotypes in glioma C6 cells via MEK/ERK signaling. In order to clarify the molecular mechanism underlying the effects of TMZ in regulating the growth and motility of glioma C6 cells, the present study examined the activities of members of the MAPK pathways,
A

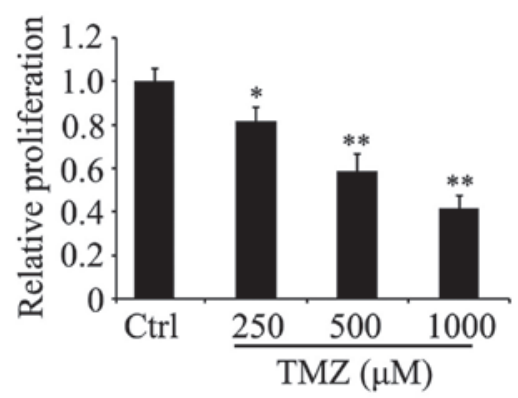

B

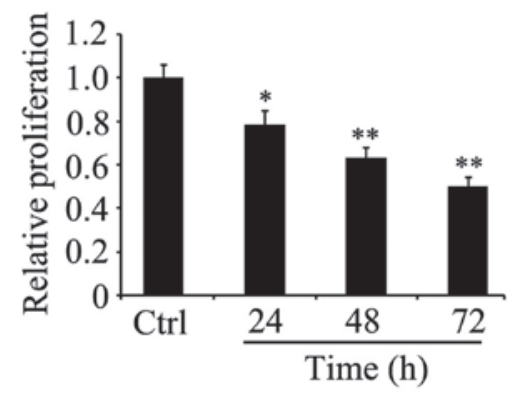

Figure 1. TMZ inhibits the proliferation of glioma C6 cells. The cells were cultured for $24 \mathrm{~h}$ and were then treated (A) with or without 250,500 and $1,000 \mu \mathrm{M}$ TMZ for $48 \mathrm{~h}$ or (B) with $500 \mu \mathrm{M}$ TMZ for 24,48 and $72 \mathrm{~h}$. An MTT assay was performed to assess cell proliferation. ${ }^{*} \mathrm{P}<0.05$ and ${ }^{* * *} \mathrm{P}<0.01$, vs. Ctrl. (Student's $t$-test). Data are presented as the mean \pm standard error of the mean. TMZ, temozolomide; Ctrl, untreated control cells.

$\mathbf{A}$

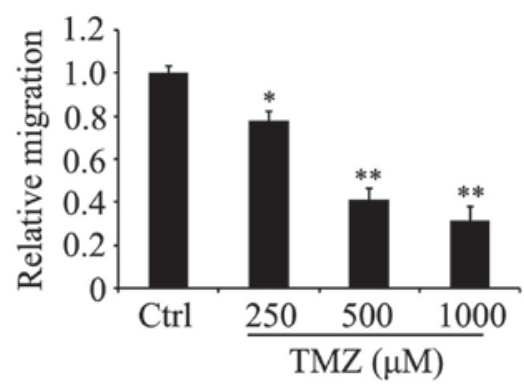

B

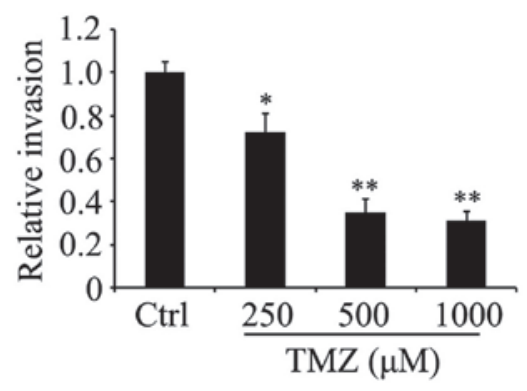

Figure 2. TMZ decreases the migration and invasion of glioma C6 cells. The cells were treated with or without 250,500 and $1,000 \mu \mathrm{M} \mathrm{TMZ}$, following which (A) cell migration and (B) invasion were analyzed using a Transwell assay. ${ }^{*} \mathrm{P}<0.05$ and ${ }^{* *} \mathrm{P}<0.01$, vs. Ctrl. (Student's $t$-test). Data are presented as the mean \pm standard error of the mean. TMZ, temozolomide; Ctrl, untreated control cells.

specifically the three terminal MAPK molecules, p38, JNK and ERK, by detecting their phosphorylation. The results showed that ERK1/2 phosphorylation was markedly decreased in the TMZ-treated cells, compared with the untreated control 
A
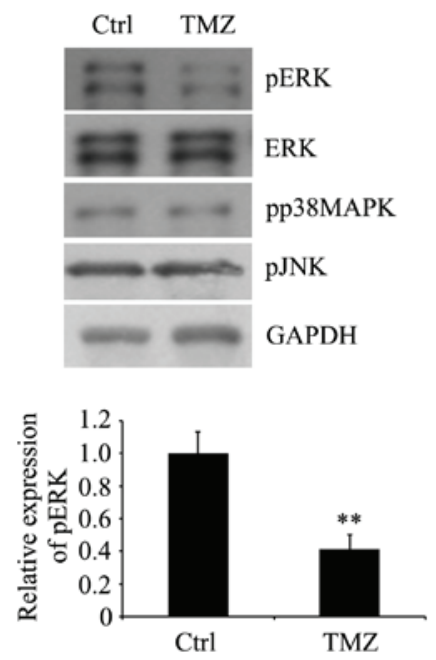

C

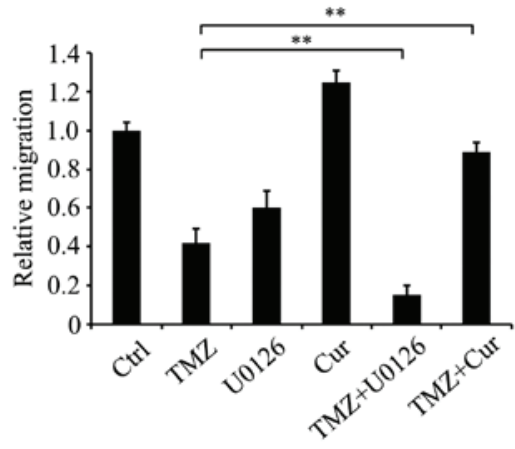

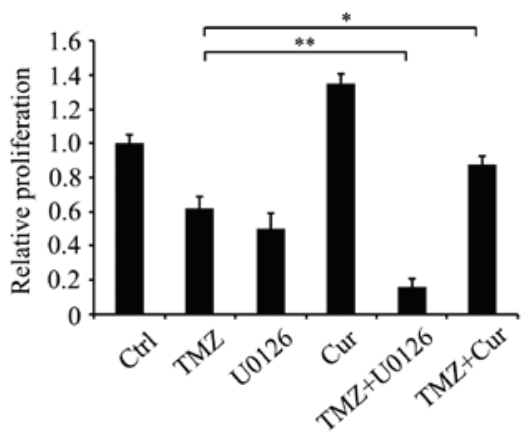

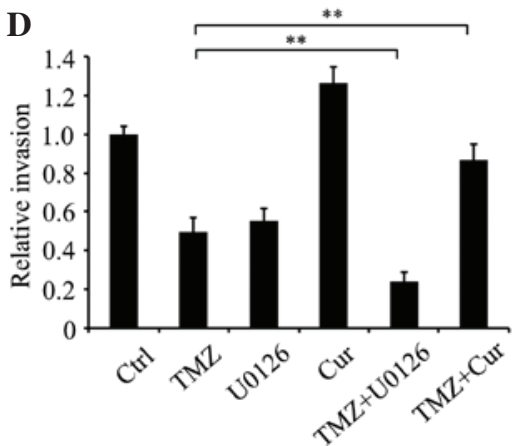

Figure 3. TMZ attenuates the proliferation and motility of glioma C6 cells via MAPK kinase/ERK signaling. (A) Expression levels of pp38MAPK, pJNK, pERK, ERK and GAPDH were detected in glioma C6 cells treated with or without $500 \mu \mathrm{M}$ TMZ for $24 \mathrm{~h}$ using western blot analysis. (B) Proliferation, (C) migration and (D) invasion of cells treated with TMZ following inhibition or activation of ERK signaling by $30 \mathrm{nM}$ U0126 and $1 \mu \mathrm{M}$ Cur, respectively. " $\mathrm{P}<0.05$ and $^{* *} \mathrm{P}<0.01$ (Student's $t$-test). Data are presented as the mean \pm standard error of the mean. TMZ, temozolomide; Ctrl, untreated control cells; Cur, curcumin; ERK, extracellular signal-regulated kinase; pERK, phosphorylated ERK; pp38MAPK, phosphorylated p38 mitogen-activated protein kinase; pJNK, phosphorylated c-Jun N-terminal kinase.
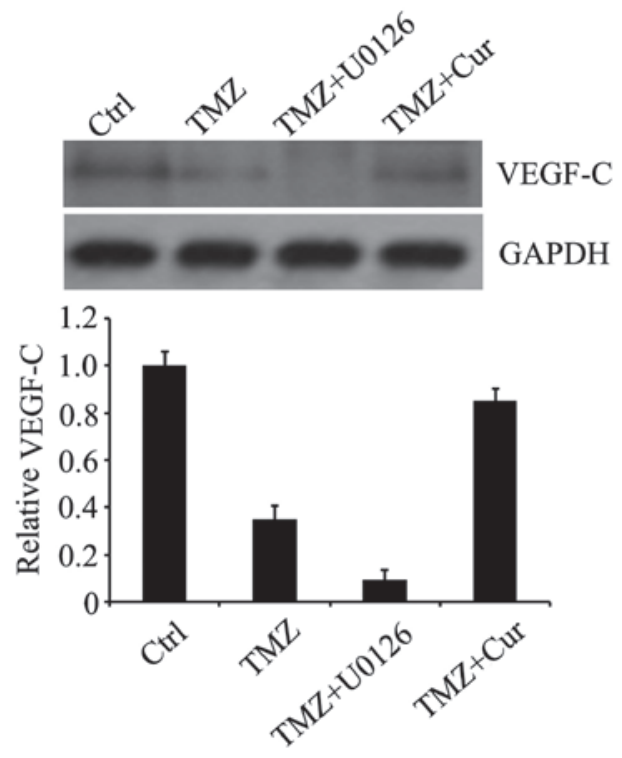

Figure 4. TMZ reduces the expression of VEGF-C via the extracellular signal-regulated kinase signaling pathway. The expression levels of VEGF-C in glioma C6 cells treated with $500 \mu \mathrm{M}$ TMZ, $30 \mathrm{nM}$ U0126 or $1 \mu \mathrm{M}$ Cur were analyzed using western blot analysis. Results are representative of three repeated experiments. Data are presented as the mean \pm standard error of the mean. TMZ, temozolomide; VEGF-C, vascular endothelial growth factor-C; Ctrl, untreated control cells; Cur, curcumin. cells (Fig. 3A). However, no significant differences were found between the TMZ-treated and the untreated groups in the expression levels of $\mathrm{p} 38$ or JNK.

To determine the effect of ERK on the function of TMZ in inhibiting the malignant phenotype of glioma C6 cells, the ERK1/2 specific inhibitor, U0126, and MEK activator, curcumin, were used. The results indicated that U0126 significantly augmented the inhibitory effect of TMZ on the proliferation (Fig. 3B), migration (Fig. 3C) and invasion (Fig. 3D) of the cells, whereas a low concentration of curcumin (30) attenuated the inhibitory effect of TMZ on the oncogenic phenotypes of the glioma C6 cells. This suggested that MEK/ERK signaling was important in the TMZ-induced inhibition of malignant phenotypes.

$T M Z$ downregulates the expression of VEGF-C via the ERK signaling pathway. As the upregulation of the growth factor, VEGF, is often involved in the abnormal growth and metastasis of glioma cells $(13,15)$ and the expression of VEGF-C in cancer cells can be affected by ERK signaling $(31,32)$, the present study investigated whether TMZ affected the expression of VEGF-C via the ERK pathway. The results indicated that TMZ decreased the expression of VEGF-C. Its expression was also reduced by the ERK1/2 inhibitor, U0126, and was 
A

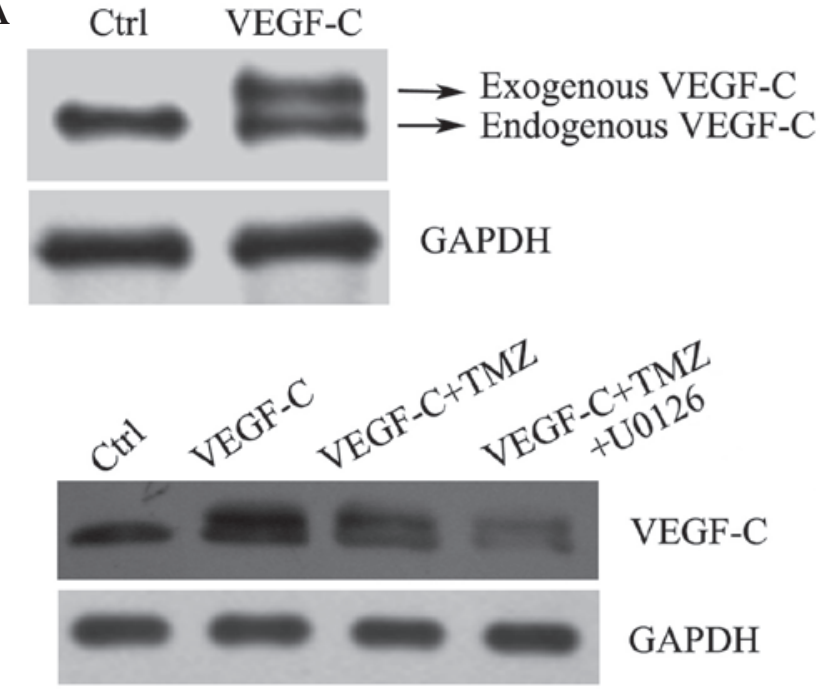

C

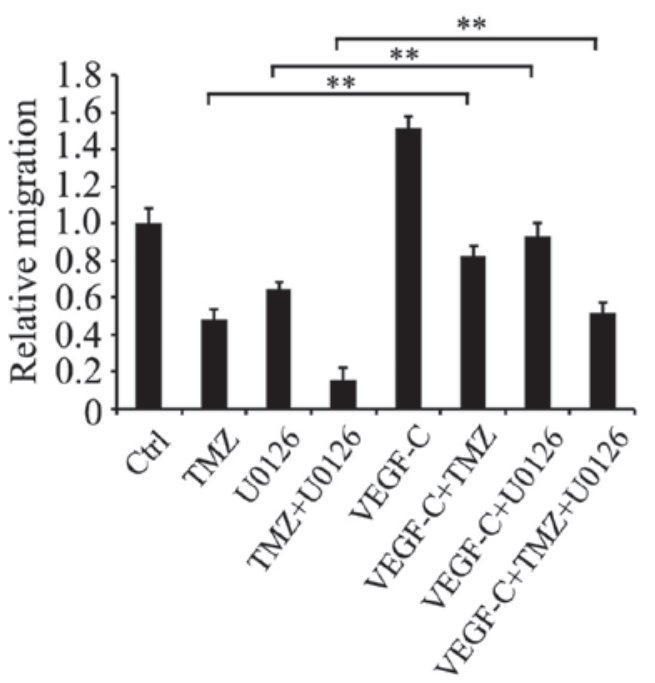

B

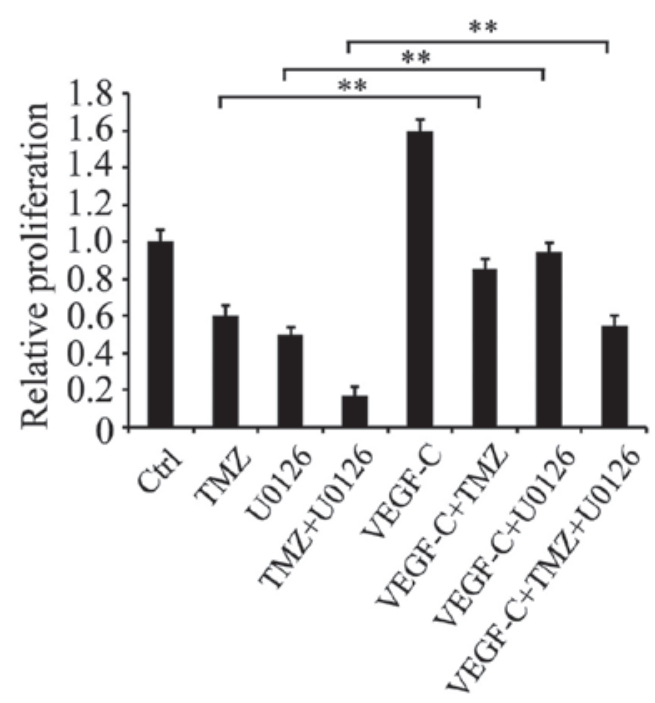

D

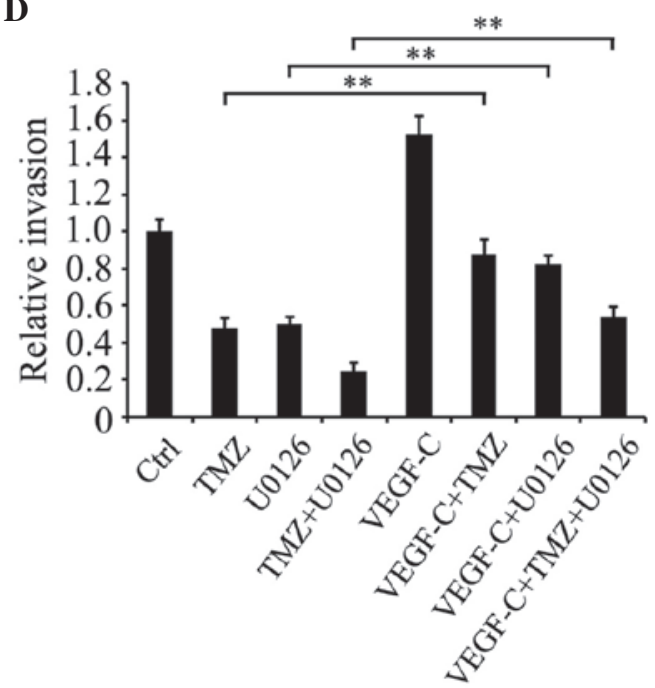

Figure 5. Overexpression of VEGF-C enhances the growth and motility of TMZ-treated glioma C6 cells. (A) Cells were induced to overexpress VEGF-C, and were then treated with $500 \mu \mathrm{M}$ TMZ and $30 \mathrm{nM}$ U0126. The protein expression of VEGF-C was detected using western blot analysis. The cells overexpressing VEGF-C and the control cells were treated with TMZ and/or U0126, following which the (B) proliferation, (C) migration and (D) invasion were analyzed using MTT and Transwell assays. ${ }^{* *} \mathrm{P}<0.01$ (Student's $t$-test). Data are presented as the mean \pm standard error of the mean. TMZ, temozolomide; Ctrl, untreated control cells; Cur, curcumin; VEGF-C. vascular endothelial growth factor-C.

restored by curcumin (Fig. 4), suggesting that VEGF-C may be the downstream effector of ERK1/2.

Overexpression of VEGF-C enhances the growth and motility of TMZ-treated glioma C6 cells. To determine whether VEGF-C is involved in the regulation of TMZ to affect glioma C6 cell growth and motility, VEGF-C was overexpressed in glioma C6 cells and the cells were treated with TMZ and/or U0126. Western blot analysis indicated that the VEGF-C protein was markedly overexpressed in the glioma C6 cells, and treatment with TMZ and U0126 downregulated the protein expression levels of exogenous and endogenous VEGF-C (Fig. 5A). The results of the MTT assay and Transwell assay showed that the overexpression of VEGF-C significantly reversed the growth, migration and invasion of the TMZ- and/or U0126-treated cells, compared with the cells without VEGF-C overexpression (Fig. 5B-D). These data suggested that $\mathrm{TMZ}$ attenuated the malignancy of glioma C6 cells, possibly through affecting the expression of VEGF-C via ERK signaling.

\section{Discussion}

TMZ is a prodrug generated from the alkylating agent dacarbazine by imidazotetrazine derivation. TMZ is often used as standard therapy for glioma, based on its ability to methylate or alkylate DNA at the O-6 or N-7 region of guanine residues leading to the death of cancer cells $(33,34)$. However, the curative effect of TMZ is often compromised due to the repair of DNA damage in tumor cells. Therefore, to use TMZ more effectively, the mechanism underlying the inhibitory effects of $\mathrm{TMZ}$ on tumor progression require further investigation. 
In the present study, it was found that TMZ significantly inhibited the ERK signaling pathway. The ERK pathway is a kinase cascade and is critical in the biological functions of cancer cells (35-38). In glioma cells, ERK signaling is closely associated with cell death, senescence, proliferation, invasion and cellular chemoresistance to TMZ (39-41). The results of the present study indicated that the phosphorylation of ERK1/2 was decreased in the TMZ-treated glioma C6 cells, compared with the untreated control cells, and was accompanied by decreased proliferation, migration and invasion. These decreases were augmented by the ERK1/2 specific inhibitor, U0126, and were attenuated by the MEK activator, curcumin, suggesting that TMZ inhibited the oncogenic phenotypes of the glioma C6 cells, possibly by inhibiting ERK signaling.

VEGF-C is a member of the VEGF family and is involved in the malignancy of several types of tumor, including those of colorectal, glioma, breast and prostate cancer (42-47). It has been reported that VEGF-C can enhance cell growth, migration and metastasis to promote tumor progression (48-52). In the present study, the expression of VEGF-C was decreased in the TMZ-treated glioma C6 cells, and overexpression of VEGF-C attenuated the inhibitory effects of TMZ on cell proliferation, migration and invasion. VEGF-C also enhanced cell growth and motility, compared with the TMZ-treated cells without VEGF-C overexpression, although they remained lower, compared with those in the untreated control cells suggesting that there other signaling pathways or proteins may be involved in the modulation. The data obtained in the present study indicated that TMZ inhibited tumor oncogenic phenotypes, including proliferation and motility, at least in part, by downregulating the expression of VEGF-C in the glioma C6 cells.

It has been reported that the expression of several growth factors, including VEGF-C are regulated by ERK1/2 signaling (31-53). In the present study, it was found that TMZ downregulated ERK signaling and decreased the expression of VEGF-C. It was hypothesized that TMZ decreases the expression of VEGF-C through inhibiting the ERK signaling pathway in glioma C6 cells. As expected, the inhibition of ERK1/2 by its inhibitor, U0126, decreased the expression of VEGF-C, whereas its expression was upregulated by the MEK activator, curcumin, confirming the hypothesis. However, the transcription factors involved in modulating the expression of VEGF-C remain to be fully elucidated.

In conclusion, the data obtained in the present study indicated that ERK signaling was involved in the control of TMZ on the oncogenic phenotypes of glioma C6 cells, and VEGF-C was critical role in its modulation. In addition, the results suggests that TMZ combined with ERK1/2 inhibitors may be a more effective therapeutic approach in the treatment of glioma.

\section{References}

1. McDonald KL, O'Sullivan MG, Parkinson JF, Shaw JM, Payne CA, Brewer JM, Young L, Reader DJ, Wheeler HT, Cook RJ, et al: IQGAP1 and IGFBP2: Valuable biomarkers for determining prognosis in glioma patients. J Neuropathol Exp Neurol 66: 405-417, 2007.

2. Goodenberger ML and Jenkins RB: Genetics of adult glioma. Cancer Genet 205: 613-621, 2012.
3. Zhang H, Ma L, Wang Q, Zheng X, Wu C and Xu BN: Role of magnetic resonance spectroscopy for the differentiation of recurrent glioma from radiation necrosis: A systematic review and meta-analysis. Eur J Radiol 83: 2181-2189, 2014.

4. Wang X, Zhao HY, Zhang FC, Sun Y, Xiong ZY and Jiang XB: Dendritic cell-based vaccine for the treatment of malignant glioma: A systematic review. Cancer Invest 32: 451-457, 2014.

5. Balenci L, Clarke ID, Dirks PB, Assard N, Ducray F, Jouvet A Belin MF, Honnorat $\mathbf{J}$ and Baudier J: IQGAP1 protein specifies amplifying cancer cells in glioblastoma multiforme. Cancer Res 66: 9074-9082, 2006.

6. Walbert $\mathrm{T}$ and Chasteen K: Palliative and supportive care for glioma patients. Cancer Treat Res 163: 171-184, 2015.

7. Newlands ES, Stevens MF, Wedge SR, Wheelhouse RT and Brock C: Temozolomide: A review of its discovery, chemical properties, pre-clinical development and clinical trials. Cancer Treat Rev 23: 35-61, 1997.

8. Stevens MF, Hickman JA, Langdon SP, Chubb D, Vickers L, Stone R, Baig G, Goddard C, Gibson NW, Slack JA, et al: Antitumor activity and pharmacokinetics in mice of 8-carbam oyl-3-methyl-imidazo[5,1-d]-1,2,3,5-tetrazin-4(3H)-one (CCRG 81045; M \& B 39831), a novel drug with potential as an alternative to dacarbazine. Cancer Res 47: 5846-5852, 1987.

9. Lewis TS, Shapiro PS and Ahn NG: Signal transduction through MAP kinase cascades. Adv Cancer Res 74: 49-139, 1998.

10. Rubinfeld $\mathrm{H}$ and Seger R: The ERK cascade: A prototype of MAPK signaling. Mol Biotechnol 31: 151-174, 2005.

11. Luttrell LM: 'Location, location, location': Activation and targeting of MAP kinases by $\mathrm{G}$ protein-coupled receptors. J Mol Endocrinol 30: 117-126, 2003.

12. Auf G, Jabouille A, Delugin M, Guérit S, Pineau R, North S, Platonova N, Maitre M, Favereaux A, Vajkoczy P, et al: High epiregulin expression in human U87 glioma cells relies on IRE1a and promotes autocrine growth through EGF receptor. BMC Cancer 13: 597, 2013.

13. Clara CA,Marie SK, de Almeida JR, Wakamatsu A, Oba-Shinjo SM, Uno M, Neville M and Rosemberg S: Angiogenesis and expression of PDGF-C, VEGF, CD105 and HIF-1 $\alpha$ in human glioblastoma. Neuropathology 34: 343-352, 2014.

14. Li L, Puliyappadamba VT, Chakraborty S, Rehman A, Vemireddy V, Saha D, Souza RF, Hatanpaa KJ, Koduru P, Burma S, et al: EGFR wild type antagonizes EGFRvIII-mediated activation of Met in glioblastoma. Oncogene 34: 129-134, 2015.

15. Burrell K, Singh S, Jalali S, Hill RP and Zadeh G: VEGF regulates region-specific localization of perivascular bone marrow-derived cells in Glioblastoma. Cancer Res 74: 3727-3739, 2014.

16. Xie J, Ma YH, Wan M, Zhan RY and Zhou YQ: Expression of dedifferentiation markers and multilineage markers in U251 glioblastoma cells with silenced EGFR and FGFR genes. Oncol Lett 7: 131-136, 2014.

17. Zheng H, Ying H, Yan H, Kimmelman AC, Hiller DJ, Chen AJ, Perry SR, Tonon G, Chu GC, Ding Z, et al: p53 and Pten control neural and glioma stem/progenitor cell renewal and differentiation. Nature 455: 1129-1133, 2008.

18. Höland K, Boller D, Hagel C, Dolski S, Treszl A, Pardo OE, Cwiek P, Salm F, Leni Z, Shepherd PR, et al: Targeting class IA PI3K isoforms selectively impairs cell growth, survival, and migration in glioblastoma. PLoS One 9: e94132, 2014.

19. Sun Y, Zhang W, Chen D, Lv Y, Zheng J, Lilljebjörn H, Ran L, Bao Z, Soneson C, Sjögren HO, et al: A glioma classification scheme based on coexpression modules of EGFR and PDGFRA. Proc Natl Acad Sci USA 111: 3538-3543, 2014.

20. Lee JS, Xiao J, Patel P, Schade J, Wang J, Deneen B, Erdreich-Epstein A and Song HR: A novel tumor-promoting role for nuclear factor IA in glioblastomas is mediated through negative regulation of $\mathrm{p} 53, \mathrm{p} 21$, and PAI1. Neuro Oncol 16: 191-203, 2014.

21. Holland EC, Celestino J, Dai C, Schaefer L, Sawaya RE and Fuller GN: Combined activation of Ras and Akt in neural progenitors induces glioblastoma formation in mice. Nat Genet 25: 55-57, 2000.

22. McNamara MG, Sahebjam S and Mason WP: Emerging biomarkers in glioblastoma. Cancers (Basel) 5: 1103-1119, 2013.

23. Rios A, Hsu SH, Blanco A, Buryanek J, Day AL, McGuire MF and Brown RE: Durable response of glioblastoma to adjuvant therapy consisting of temozolomide and a weekly dose of AMD3100 (plerixafor), a CXCR4 inhibitor, together with lapatinib, metformin and niacinamide. Oncoscience 3: 156-163, 2016. 
24. Berte N, Piee-Staffa A, Piecha N, Wang M, Borgmann K, Kaina B and Nikolova T: Targeting homologous recombination by pharmacological inhibitors enhances the killing response of glioblastoma cells treated with alkylating drugs. Mol Cancer Ther 15: 2665-2678, 2016.

25. Shaaban S, Alsulami M, Arbab SA, Ara R, Shankar A, Iskander A, Angara K, Jain M, Bagher-Ebadian H, Achyut BR and Arbab AS: Targeting bone marrow to potentiate the anti-tumor effect of tyrosine kinase inhibitor in preclinical rat model of human glioblastoma. Int J Cancer Res 12: 69-81, 2016.

26. Qiu Z, Yue S, Chang J and Wang G: Phosphatidylinositide 3-kinase inhibitor BKM120 suppresses proliferation and promotes apoptosis of U251 glioblastoma cells. Xi Bao Yu Fen Zi Mian Yi Xue Za Zhi 32: 936-939, 2016.

27. Favata M, Horiuchi KY, Manos EJ, Daulerio AJ, Stradley DA, Feeser WS, Van Dyk DE, Pitts WJ, Earl RA, Hobbs F, et al: Identification of a novel inhibitor of mitogen-activated protein kinase kinase. J Biol Chem 273: 18623-18632, 1998.

28. DeSilva D Jones EA, Favata MF, Jaffee BD, Magolda RL, Trzaskos JM and Scherle PA: Inhibition of mitogen-activated protein kinase kinase blocks $\mathrm{T}$ cell proliferation but does not induce or prevent anergy. J Immunol 160: 4175-4181, 1998.

29. Duncia JV, Santella JB 3rd, Higley CA, Pitts WJ, Wityak J, Frietze WE, Rankin FW, Sun JH, Earl RA, Tabaka AC, Teleha CA, et al: MEK inhibitors: The chemistry and biological activity of U0126, its analogs, and cyclization products. Bioorg Med Chem Lett 8: 2839-2844, 1998.

30. Son S, Kim KT, Cho DC, Kim HJ, Sung JK and Bae JS: Curcumin stimulates proliferation of spinal cord neural progenitor cells via a mitogen-activated protein kinase signaling pathway. J Korean Neurosurg Soc 56: 1-4, 2014.

31. Chen X, Xie Q, Cheng X, Diao X, Cheng Y, Liu J, Xie W, Chen Z and Zhu B: Role of interleukin-17 in lymphangiogenesis in non-small-cell lung cancer: Enhanced production of vascular endothelial growth factor $\mathrm{C}$ in non-small-cell lung carcinoma cells. Cancer Sci 101: 2384-2390, 2010.

32. Zhu C, Qi X, Chen Y, Sun B, Dai Y and Gu Y: PI3K/Akt and MAPK/ERK1/2 signaling pathways are involved in IGF-1-induced VEGF-C upregulation in breast cancer. J Cancer Res Clin Oncol 137: 1587-1594, 2011.

33. Zhou X, Liao X, Zhang B, He H, Shui Y, Xu W, Jiang C, Shen L and Wei Q: Recurrence patterns in patients with high-grade glioma following temozolomide-based chemoradiotherapy. Mol Clin Oncol 5: 289-294, 2016.

34. Dong F: Metalloproteases involved in the Temozolomide (TMZ) resistance of U87-MG glioma cells. Angenommen vom Fachbereich Medizin der Philipps-Universität Marburg ,April 3, 2013.

35. Balmanno K and Cook SJ: Tumour cell survival signalling by the ERK1/2 pathway. Cell Death Differ 16: 368-377, 2009.

36. McCubrey JA, Steelman LS, Chappell WH, Abrams SL, Wong EW, Chang F, Lehmann B, Terrian DM, Milella M, Tafuri A, et al: Roles of the Raf/MEK/ERK pathway in cell growth, malignant transformation and drug resistance. Biochim Biophys Acta 1773: 1263-1284, 2007.

37. Neuzillet C, Tijeras-Raballand A, de Mestier L, Cros J, Faivre S and Raymond E: MEK in cancer and cancer therapy. Pharmacol Ther 141: 160-171, 2014.

38. Yoon S and Seger R: The extracellular signal-regulated kinase: Multiple substrates regulate diverse cellular functions. Growth Factors 24: 21-44, 2006.
39. Gentile MT, Ciniglia C, Reccia MG, Volpicelli F, Gatti M, Thellung S, Florio T, Melone MA and Colucci-D'Amato L: Ruta graveolens L. induces death of glioblastoma cells and neural progenitors, but not of neurons, via ERK 1/2 and AKT activation. PLoS One 10: $\mathrm{e} 0118864,2015$.

40. Liu Q, Xu X, Zhao M, Wei Z, Li X, Zhang X, Liu Z, Gong Y and Shao C: Berberine induces senescence of human glioblastoma cells by downregulating the EGFR-MEK-ERK signaling pathway. Mol Cancer Ther 14: 355-363, 2015.

41. Han S, Li Z, Master LM, Master ZW and Wu A: Exogenous IGFBP-2 promotes proliferation, invasion, and chemoresistance to temozolomidein glioma cells via the integrin $\beta 1$-ERK pathway. Br J Cancer 111: 1400-1409, 2014.

42. Tacconi C, Correale C, Gandelli A, Spinelli A, Dejana E, D'Alessio S and Danese S: Vascular endothelial growth factor $C$ disrupts the endothelial lymphatic barrier to promote colorectal cancer invasion. Gastroenterology 148: 1438-1451.e8, 2015.

43. Carpenter RL, Paw I, Zhu H, Sirkisoon S, Xing F, Watabe K, Debinski W and Lo HW: The gain-of-function GLI1 transcription factor TGLI1 enhances expression of VEGF-C and TEM7 to promote glioblastoma angiogenesis. Oncotarget 6: 22653-22665, 2015.

44. Pang XH, Tian H, Liu ZY, Li SM, Liu ST and Tian GP. Significance and expression of vascular endothelial growth factor-C (VEGF-C) in esophageal squamous carcinoma and glioma. Ai Zheng 22: 1166-1169, 2003 (In Chinese).

45. Wang CA, Harrell JC, Iwanaga R, Jedlicka P and Ford HL: Vascular endothelial growth factor $\mathrm{C}$ promotes breast cancer progression via a novel antioxidant mechanism that involves regulation of superoxide dismutase 3. Breast Cancer Res 16: 462, 2014.

46. Varney ML and Singh RK: VEGF-C-VEGFR3/Flt4 axis regulates mammary tumor growth and metastasis in an autocrine manner. Am J Cancer Res 5: 616-628, 2015.

47. Sun GG, Wang YD, Cui DW, Cheng YJ and Hu WN: EMP1 regulates caspase-9 and VEGFC expression and suppresses prostate cancer cell proliferation and invasion. Tumour Biol 35: 3455-3462, 2014

48. Khromova N, Kopnin P, Rybko V and Kopnin BP: Downregulation of VEGF-C expression in lung and colon cancer cells decelerates tumor growth and inhibits metastasis via multiple mechanisms. Oncogene 31: 1389-1397, 2012.

49. Chen Y, Jiang L, She F, Tang N, Wang X, Li X, Han S and Zhu J: Vascular endothelial growth factor-C promotes the growth and invasion of gallbladder cancer via an autocrine mechanism. Mol Cell Biochem 345: 77-89, 2010.

50. Su JL, Chen PS, Chien MH, Chen PB, Chen YH, Lai CC, Hung MC and Kuo ML: Further evidence for expression and function of the VEGF-C/VEGFR-3 axis in cancer cells. Cancer Cell 13: 557-560, 2008.

51. Su JL, Yang PC, Shih JY, Yang CY, Wei LH, Hsieh CY, Chou CH, Jeng YM, Wang MY, Chang KJ, et al: The VEGF-C/Flt-4 axis promotes invasion and metastasis of cancer cells. Cancer Cell 9: 209-223, 2006

52. Timoshenko AV, Rastogi S and Lala PK: Migration-promoting role of VEGF-C and VEGF-C binding receptors in human breast cancer cells. British J Cancer 97: 1090-1098, 2007.

53. Takahashi O, Komaki R, Smith PD, Jürgensmeier JM, Ryan A, Bekele BN, Wistuba II, Jacoby JJ, Korshunova MV, Biernacka A, et al: Combined MEK and VEGFR inhibition in orthotopic human lung cancer models results in enhanced inhibition of tumor angiogenesis, growth, and metastasis. Clin Cancer Res 18: 1641-1654, 2012. 